\title{
Neuronal toll-like receptors and neuro-immunity in Parkinson's disease, Alzheimer's disease and stroke
}

\author{
Carmen D. Rietdijk ${ }^{1}$, Richard J. A. van Wezel ${ }^{2,3}$, Johan Garssen ${ }^{1,4}$, Aletta D. Kraneveld ${ }^{1}$ \\ ${ }^{1}$ Division of Pharmacology, Utrecht Institute for Pharmaceutical Sciences, Faculty of Science, Utrecht University, 3584 CG Utrecht, \\ the Netherlands. \\ ${ }^{2}$ Department of Biomedical Signals and Systems, MIRA, University of Twente, 7522 NB Enschede, the Netherlands. \\ ${ }^{3}$ Department of Biophysics, Donders Institute for Brain, Cognition and Behaviour, Radboud University Nijmegen, 6500 GL Nijmegen, \\ the Netherlands. \\ ${ }^{4}$ Nutricia Research, Utrecht Science Park, 3584 CT Utrecht, the Netherlands.
}

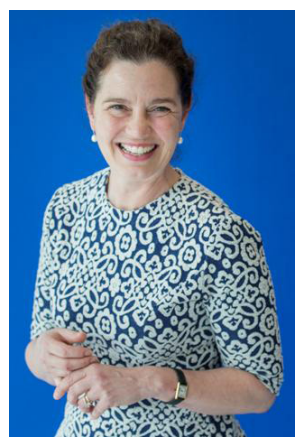

Aletta D. Kraneveld's research team focuses on the role of the gut-immune-brain-axis in chronic inflammatory and neurological disorders combining expertises of immunology, pharmacology, microbiology and neuroscience. She has published over 80 papers.

\section{A B S T R A C I}

Toll-like receptors (TLRs) are part of the innate immune system and can initiate an immune response upon exposure to harmful microorganisms. Neuronal TLRs are considered to be part of an established framework of interactions between the immune system and the nervous system, the major sensing systems in mammals. TLRs in the nervous system and neuronal TLRs are suspected to be important during inflammation and neurodegenerative diseases. The aim of this review is to offer an overview of the current knowledge about TLRs in neurodegenerative pathologies, with a focus on Parkinson's disease. More research focusing on the role of TLRs in health and disease of the nervous system is needed and remains to be explored.

Key words: Neuron; toll-like receptor; Parkinson's disease; Alzheimer's disease; stroke; neurodegeneration; neurodevelopment; infection

\section{INTRODUCTION}

Publications were first selected about toll-like receptors (TLRs) on neurons, and on TLRs for which functional information in neurons was available. Publications were also selected for their focus on neurodegenerative diseases. The last literature search

Corresponding Author: Dr. Aletta D. Kraneveld, Division of

Pharmacology, Utrecht Institute for Pharmaceutical Sciences,

Faculty of Science, Utrecht University, Universiteitsweg 99, 3584

CG Utrecht, the Netherlands. E-mail: A.D.Kraneveld@uu.nl

\begin{tabular}{|l|l|}
\hline \multicolumn{3}{|c|}{ Access this article online } \\
\hline Quick Response Code: & Website: \\
\hline & www.nnjournal.net \\
\cline { 2 - 3 } & \\
\hline
\end{tabular}

was performed on April 14th 2015. This review aims to offer an overview of the current knowledge about TLRs in the nervous system and to show the relevance of these receptors in neurodegenerative pathologies, with a focus on Parkinson's disease (PD).

TLRs are the mammalian orthologue of Drosophila Melanogaster's toll receptor discovered in 1988. ${ }^{[1]}$ TLRs are part of the innate immune system and belong

This is an open access article distributed under the terms of the Creative Commons Attribution-NonCommercial-ShareAlike 3.0 License, which allows others to remix, tweak, and build upon the work non-commercially, as long as the author is credited and the new creations are licensed under the identical terms.

For reprints contact: service@oaepublish.com

Cite this article as: Rietdijk CD, van Wezel RJA, Garssen J, Kraneveld AD. Neuronal toll-like receptors and neuro-immunity in Parkinson's disease, Alzheimer's disease and stroke. Neuroimmunol Neuroinflammation 2016;3:27-37

Received: 17-06-2015; Accepted: 20-09-2015 
to the pattern recognition receptors [Figure 1]. They can recognize both small molecular motifs conserved across microbes (pathogen-associated molecular pattern or PAMP) [Figure 2], and endogenous molecules generated during inflammation or tissue damage (damage associated molecular pattern or DAMP). ${ }^{[2-5]}$ TLRs can initiate an acute inflammatory reaction and subsequently can coordinate the activation of the adaptive immune system. To date, thirteen TLRs are known, of which ten (TLR1-10) have been described in humans ${ }^{[6]}$ The cell surface TLRs recognize PAMPs that are mainly constituent of the bacterial cell wall or are expressed on the bacterial cell surface, such as lipopeptides and peptidoglycal (TLR1/TLR2, TLR2/ TLR6, TLR2/TLR10), lipopolysaccharide (LPS) (TLR4) and flagellin (TLR5). In contrast, the intracellular TLRs mainly recognize microbial nucleic acid including viral double-strand RNAs (TLR3), singlestrand RNAs (TLR7 and TLR8) and CpG ODN (TLR9). ${ }^{[7]}$ TLRs can employ two second messenger pathways; the myeloid differentiation primary response gene 88 (MyD88) pathway, activating nuclear factor к-lightchain-enhancer of activated B cells (NF-kB), or the TIRdomain-containing adapter-inducing interferon- $\beta$ (TRIF) pathway, activating interferon regulatory factor 3 (IRF3) [Figure 2]. NF- $\mathrm{KB}$ controls DNA transcription resulting in the production of pro-inflammatory cytokines such as tumor necrosis factor $\alpha(\mathrm{TNF} \alpha)$, interleukin (IL)1 $\beta$ and IL6. ${ }^{[7,8]}$ IRF3 is an interferon (IFN) regulatory factor leading to the production of antiviral type I IFN. ${ }^{[2,7]}$

The presence of TLRs on immune cells and epithelial cells is well known, but their expression is not restricted to these cell types. Glial cells and neurons express TLRs in both the peripheral nervous system (PNS) and the central nervous system (CNS) [Figure 3], allowing neurons to act as immune cells. ${ }^{[9-15]}$ More specifically, in the CNS neurons, astrocytes and microglial cells express TLR1-9, whereas oligodendrocytes express only TLR2 and TLR3. ${ }^{[16-20]}$ Peripheral neurons also express TLR1-9 and enteric glial cell express TLR15, TLR7 and TLR9. ${ }^{[13,14,21-23]}$ Neuronal TLR signaling

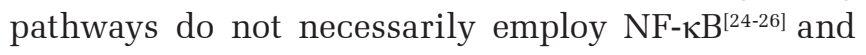
may involve the glycogen synthase kinase $3 \beta$ (GSK3 $\beta$ ), jun-N-terminal kinase (JNK) and phosphatidylinositol 3-kinase/protein kinase B (PI3K/AKT) pathways. ${ }^{[27-29]}$ Interaction between neurons and the immune system has already been reported, setting the scene for neurons acting as immune cells. ${ }^{[30-34]}$ It has been reported that neuronal TLRs are involved in the development and homeostasis of the nervous system, and notably in several neurodegenerative diseases. ${ }^{[35,36]}$ Both TLR2 and TLR4 are involved in neuronal apoptosis, development and survival in the context

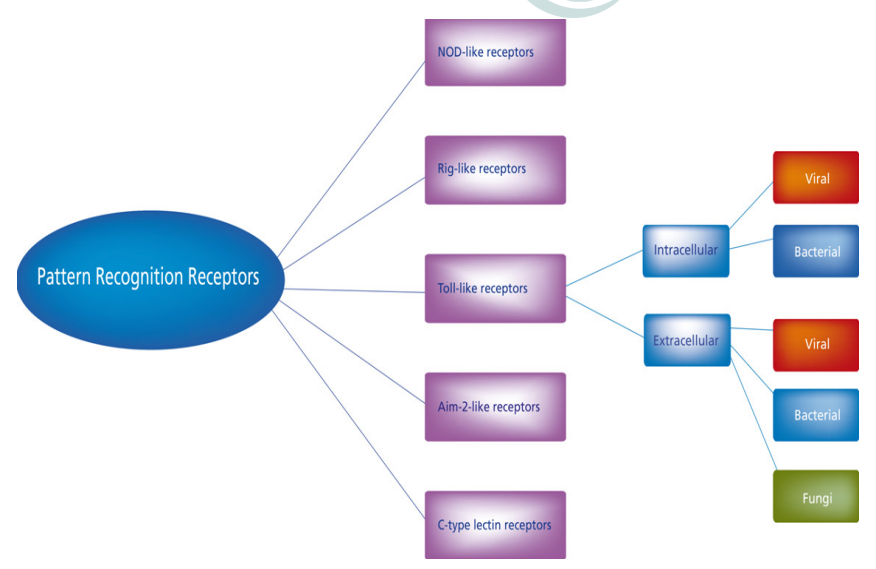

Figure 1: Toll like receptors are part of the innate immune system and belong to the pattern recognition receptors

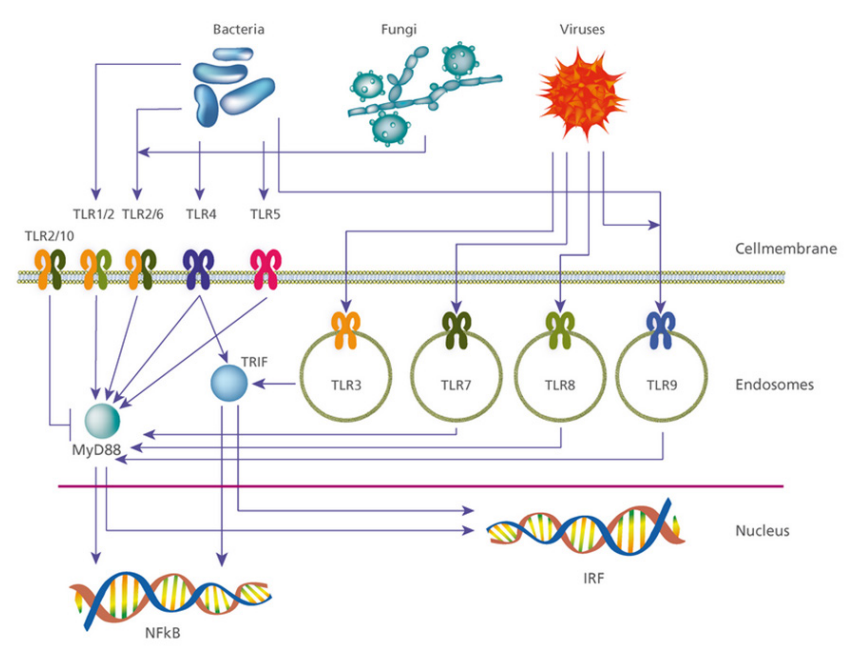

Figure 2: Different pathogens activate different TLRs. TLRs signal through two different pathways using myeloid differentiation primary response gene 88 (MyD88) and TIR-domain-containing adapter-inducing interferon $\beta$, leading to activation of NF-kB and IRF respectively NF-kB leads to DNA transcription and cytokine production, while IRF leads to interferon production. TLRs: toll like receptors; NF-kB: nuclear factor $\kappa$-light-chain-enhancer of activated $B$ cells; IRF: interferon regulatory factor
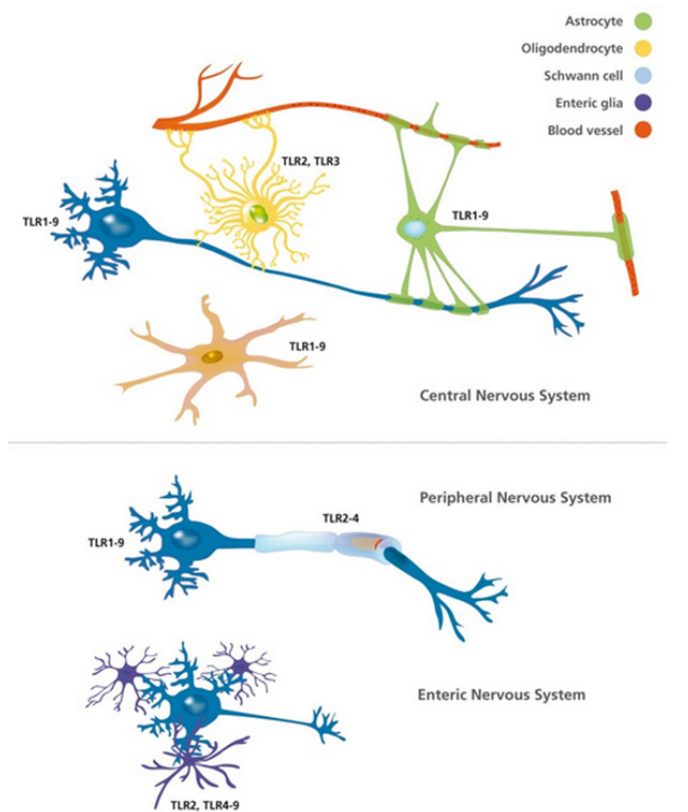

Figure 3: TLRs are differentially expressed by neurons and glial cells of the central, peripheral and enteric nervous system. TLRs: toll like receptors 
of opioids exposure, ischemia/stroke, viral infections and Alzheimer's disease (AD), ${ }^{[28,29,37-43]}$ via GSK3 $\beta$ and JNK. ${ }^{[28,29]}$ TLR3 and TLR8 negatively regulate neuronal development and axonal growth and are involved in fighting viral infections, ${ }^{[9,16,24,25,27,44-46]}$ through PI3K pathway. ${ }^{[27]}$ Other information also indicates a role for TLRs in the nervous system during disease. TLR1-5, TLR8 and TLR9 are overexpreesed in PD and multiple systems atrophy (MSA) patients and in animal models of PD, AD, MSA and amyotrophic lateral sclerosis. ${ }^{[4-53]}$ Of these receptors, TLR2 and TLR4 are of special interest in PD, as will become clear in the sections dedicated to these TLRs. The current knowledge about TLR2 and TLR4 in PD has focused heavily on microglia, and not so much on neuronal TLRs. To better understand the potential importance of neuronal TLRs in neurodegeneration and specifically in $\mathrm{PD}, \mathrm{AD}$ and stroke the current knowledge about the function of neuronal TLRs in neuronal development and neurodegenerative diseases will be discussed here.

\section{NERVOUS SYSTEM TLR EXPRESSION}

This section will cover the expression of TLRs on neurons and glial cells [Figure 3]. To discuss the function of TLRs on neurons it is important to know whether neurons express TLRs. For the convenience of the reader, the information about expression has been organized based on location in the nervous system, and stage of life. To discuss the function of TLRs in the nervous system it is also necessary to first address whether glial cells express TLRs, because of their biological relevance for the functioning of the CNS and PNS.

\section{Neuronal TLR expression}

TLR expression on primary neurons has been found in several species, amongst which are humans, ${ }^{[10,12,13,15,16,45]}$ mice, ${ }^{[13,14,26,28,43,54,55]}$ and rats. ${ }^{[10,27,56,57]}$ Neuronal TLRs are present in both parts of the nervous system; the $\mathrm{CNS}^{[12,26,28]}$ and the PNS. ${ }^{[10,13,14,43,54,57]}$ Expression of TLRs by neurons has been confirmed at mRNA level, ${ }^{[14,21,24,28,43]}$ and protein level. ${ }^{[10,13,24,26,28,43,54,57,58]}$ Most results on neuronal TLRs come from experiments in embryonic neurons because these are easier to culture than neurons from adult animals. Nonetheless, neurons express TLRs throughout life, starting at the embryonic stage, ${ }^{[14,24,26,28,43,58]}$ followed by the postnatal, ${ }^{[54]}$ and the young stages, ${ }^{[10,56]}$ and finally in the adult stage of life. ${ }^{[10,12,13,21,58,55,57]}$ Taken together, these data offer many opportunities to study neuronal TLRs for a wide range of research questions, since it is reported that TLRs are expressed throughout the nervous system and throughout the lifespan of animals.
TLR expression has also been found in several neuronal cell lines. The teratocarcinoma derived human post-mitotic dopaminergic neuronal cell line NT2-N expresses TLR3..$^{[9,59-61]}$ TLR3 is also expressed by human neuroblastoma cell lines (including noradrenergic cell lines, CHP-212 and SK-NSH; a noradrenergic and gamma-aminobutyric cell line, SHSY5Y; SH-SY5Y and a noradrenergic and dopaminergic cell line, BE(2)-C) and primary human neuroblastic cells. ${ }^{[27,44,45,59]}$ The rat neuroblastoma cell line B103 expresses TLR2. ${ }^{[38]}$ The expression of TLR1-9 has been reported in the human CHP-212 neuroblastoma cell line. ${ }^{[16]}$ Although cell lines are further removed from their original biological environment than primary cells, they do offer a more readily available source of material for further research towards understanding the functions of neuronal TLRs.

\section{Glial TLR expression}

The importance of glial TLRs in neurodegeneration is indisputable. ${ }^{[19,32,53,62-65]}$ Glial cells come in many shapes and sizes, and have a critical role in the CNS and PNS, such as immune surveillance, the regulation of chemical environment and the production of the myelin sheath, which makes them biologically relevant to the functioning of neurons.

Glial cells are a heterogeneous group of cells all of them expressing TLRs. Microglia act as immune surveillance of the CNS and express TLR1-9 in both humans and mice. ${ }^{[19,20]}$ Astrocytes regulate the chemical environment of neurons, and they express TLR1-9 in mice and TLR1, TLR3-5 and TLR9 in humans, while TLR2 and TLR6-8 were not detected in human astrocytes. ${ }^{[17,18]}$ Oligodendrocytes and Schwann cells respectively produce the myelin sheath around neuronal axons in the CNS and PNS. Schwann cells express TLR1-9 in mice, ${ }^{[14,66]}$ while only TLR2 has been studied and detected in humans, ${ }^{[67]}$ whereas TLR4 has been studied and detected in rats. ${ }^{[68,69]}$ Human oligodendrocytes only express TLR2 and TLR3, while TLR1 and TLR4-9 were undetectable. ${ }^{[20]}$ In glial cells of the enteric nervous system TLR2 -9 have been found, while TLR1 is absent. ${ }^{[13,22,70]}$

\section{NEURONAL TLR FUNCTIONALITY}

Here we provide a comprehensive overview of the current knowledge about TLR functionality in the nervous system in relation to neurodegeneration. Specific information about neurons, microglia, and other cell types is included when appropriate.

\section{TLR2}

TLR2 is a TLR family member that is able to recognize bacterial lipopolypeptides and peptidoglycans. 
TLR2 forms heterodimers with TLR1 and TLR6 and mediates the host response to Gram-positive bacteria and yeast infections via stimulation of $\mathrm{NF}-\kappa \mathrm{B}$ signaling pathway. ${ }^{[71]}$ Recently, it has been demonstrated that TLR2 can also form a heterodimer with TLR10 acting as an inhibitory receptor with immune suppressing effects. ${ }^{[72]}$

\section{$P D$}

Clinical studies have shown that TLR2 expression is increased in PD. In particular, one study revealed specific increase in microglial TLR2 in the substantia nigra and the hippocampus in the early stages of the disease, but not during the late stages, ${ }^{[73]}$ while another study showed an increase in TLR2 in the striatum of advanced PD patients. ${ }^{[74]}$ These results indicate that expression of TLR2 in either early or advanced PD could be region-specific, and that TLR2 is not necessarily expressed in all regions at the same time. The involvement of TLR2 in PD might be two-dimensional: microglial activation of TLR2 can induce neurotoxicity or TLR2 can be important for the clearance of $\alpha$-synuclein, thus being neuroprotective.

In support of this function is the evidence that TLR2 polymorphism tends to be associated with an increased risk of PD. This polymorphism results in altered TLR2 promoter transcriptional activity leading to lower expression of TLR2. ${ }^{[75,76]}$ Taken together, these findings are indirect indications of a possible role of TLR2 in the pathology of PD.

Overexpression of human $\alpha$-synuclein in mice resulted in microglial activation and an increase in TLR2 expression. ${ }^{[74]}$ Microglia seem to form a crucial link between TLR2 and PD pathology; an idea that is supported by results from cell culture studies: exposure to $\alpha$-synuclein activates cultured microglia and increases their TLR2 expression; ${ }^{[49,77]}$ it also changes the response of microglial cells to TLR1/2 stimulation by increasing their inflammatory response. ${ }^{[78]}$

It can be speculated that $\alpha$-synuclein triggers neuroinflammation through microglial TLR2, initiating a positive feedback loop by increasing TLR2 expression on the microglia, resulting in neurodegeneration and disease progression. However, it is not yet clear why this process would be limited to the early disease stage in the substantia nigra and the hippocampus, while only occurring later in the striatum, or whether and how neuronal TLR2 participates in this process.

TLR2 expression was found on microglia surrounding amyloid $\beta(\mathrm{A} \beta$ ) plaques in post-mortem brain sections and in an $\mathrm{AD}$ mouse model, raising the question whether and how TLR2 might be involved in AD pathology. ${ }^{[47,79]}$ Injecting $A \beta$ in the hippocampus of wild type (WT) mice increases TLR2 expression in microglia; $A \beta$ protein was unable to induce a microglia-dependent inflammatory response in the cortex of TLR2 deficient mice. ${ }^{[80,81]}$ The interaction between $A \beta$ and TLR2 also affects behavior; TLR2 deficient mice showed more pronounced cognitive impairments, which correlated with increased levels of $A \beta$ protein. ${ }^{[81]}$ It remains to be demonstrated whether there is a direct binding between TLR2 and the $A \beta$ protein.

AD-related damage to neurons is at least partially dependent on microglial TLR2, since the effects of $A \beta$ protein and TLR1/2 ligand on neuronal viability are additive and dependent on microglia, and the microglial inflammatory and phagocytic response to $A \beta$ protein is TLR2-dependent. ${ }^{[80,82,83]} \mathrm{A} \beta$ proteinand TLR1/2 ligand-induced microglial-mediated neuronal death is likely conferred through the release of inflammatory mediators. ${ }^{[84]}$ There is also indication for the involvement of neuronal TLR2 in AD. Neuronal TLR2 was upregulated when neuronal cultures were exposed to hydroxynonenal (HNE), an AD-related lipid peroxidation product, but not when exposed to $A \beta$ protein. ${ }^{[40]}$ HNE exposure also resulted in an increase in both phosphorylated JNK and cleaved caspase 3; however these effects were abolished by TLR4 knockout. Therefore, the functional consequence of TLR2 upregulation in neurons by HNE is not yet known.

In summary, microglial TLR2 is key in the neuroinflammatory response of $\mathrm{AD}$ pathology, but is also responsible for the clearance of $A \beta$ protein, while neuronal TLR2 might also play a part in this neuroinflammatory environment. So TLR2 can have either a beneficial or detrimental role in AD.

\section{Stroke}

Neuronal TLR2 was studied in the cerebral ischemia/ reperfusion (I/R) animal model of stroke. Cortical and hippocampal neurons of WT mice subjected to $\mathrm{I} / \mathrm{R}$ injury showed transient TLR2 protein upregulation, although upregulation in the cortex may not have been exclusively neuronal. ${ }^{[29,37,39]} \mathrm{TLR}^{-/}$mice exposed to I/R showed less brain damage, smaller infarct volumes and less neurological deficits than WT mice, and TLR2 ${ }^{-1}$ mice and mice treated with TLR2 antibody showed less inflammatory cell accumulation and reduced neuronal loss. ${ }^{[29,39,42]}$ From a treatment perspective it is interesting that the anti-inflammatory agent baicalin, used for the treatment of stroke, reduced TLR2 expression in 
hippocampal neurons after I/R injury. ${ }^{[37]}$ However, before suggesting a potential role of TLR2 in the treatment of stroke, clinical studies are needed to determine whether TLR2 is viable as a marker or target for treatment in stroke.

Animal models show that TLR2 is relevant in relation to stroke, however, they might obscure the specific importance of neuronal TLR2 in the context of glial cells. In order to isolate and study neuronal TLR2 in a stroke model, cultured neurons were exposed to glucose deprivation, a model of stroke. ${ }^{[29]}$ Increased cell death was found in WT neurons, while TLR2 ${ }^{-/}$neurons were resistant to glucose deprivation induced cell death. In a neuronal cell line oxygenglucose deprivation resulted in TLR2 upregulation and in an increase of non-apoptotic cell death. ${ }^{[85]}$ These in vitro data confirm that stroke can result in neurodegeneration through the activation of neuronal TLR2, making neuronal TLR2 a potential player in brain damage after $\mathrm{I} / \mathrm{R}$ injury in mice, independent from the influence of glial TLR2.

Information on TLR2 in the brain of patients with stroke is sorely missing and should be sought in future research, starting with investigating expression patterns in different brain regions. Also, a major focus of research should aim at distinguishing neuronal TLR2 from glial TLR2.

\section{TLR3}

TLR3 recognizes double stranded RNA associated with viral infection, and host RNA. Ligand binding induces the production of anti-viral mediators like the type I interferons (IFNs), such as IFN- $\alpha$ and $-\beta$ production by leukocytes. These IFNs stimulate macrophages and natural killer cells to elicit an anti-viral response. ${ }^{[86]}$

TLR3 has not been studied in direct relationship to neurodegenerative diseases, but work has been performed on the effect of TLR3 in the development of the nervous system. TLR3 expression decreases in the embryonic CNS during neurogenesis. ${ }^{[58]}$ Intrathecal injection of TLR3 agonist polyinosine: polycytidylic acid in postnatal day 4 mice resulted in sensory-motor deficits, neuroanatomical defects and fewer axons in the spinal cord, which was associated with neurodegeneration. ${ }^{[24]}$ The role for TLR3 in this study was demonstrated by the fact that no anatomical or behavioral problems were found in TLR3 $^{-/}$mice treated with polyinosine: polycytidylic acid. ${ }^{[24}$ It seems that TLR3 is involved in the proper development of the CNS in early fetal life, because the receptor is differentially expressed at different embryonic stages. After birth, stimulation of TLR3 results in neurodegeneration. The decrease in expression of TLR3 during neurogenesis, as found in the embryonic brain, is also found in cultured neural progenitor cells (NPCs), making NPCs more sensitive to TLR3-mediated inhibition of proliferation than mature neurons. ${ }^{[58]}$ Despite this reported decrease in TLR3 expression during neurogenesis, neurons do express functional TLR3. ${ }^{[2]}$ In primary neurons, TLR3 stimulation inhibits neurite outgrowth and causes irreversible growth cone collapse, without affecting cell survival. ${ }^{[24]}$ Different results were found in the high TLR3-expressing neuroblastoma cell line SK-N-AS, where exposure to a TLR3 ligand resulted in growth inhibition and apoptosis. ${ }^{[4]}$ The difference in results on cell viability could be due to the use of different cell types (dorsal root ganglia, ${ }^{[24]} \mathrm{NPCs},{ }^{[58]}$ and cell lines ${ }^{[44]}$, thus revealing the limits of cell culture as a model of biological processes.

Although all in vivo data are obtained from early life studies and interpretation of these data in the context of neurodegeneration must be done carefully, extrapolating these results leads to the hypothesis that stimulation of neuronal TLR3 could be detrimental in neurodegenerative diseases, especially in the context of viral infections. TLR3 is a viral sensing innate immune receptor. It is known that viral infections like influenza can cause neurodegeneration ${ }^{[87]}$ and that viruses are linked to neurodegenerative diseases:[88] specifically hepatitis C virus, Eppstein-Barr virus and human immunodeficiency virus (HIV) have been associated with PD. ${ }^{[89-91]}$ The involvement of neuronal TLRs during viral infections is discussed in more detail in a later part of this review.

\section{TLR4}

TLR4 detects LPS derived from Gram-negative bacteria and host-derived signaling molecules such as heat shock proteins, and extracellular matrix proteins, after which the innate immune system is activated, leading to an inflammatory response. ${ }^{[92-94]}$

\section{$P D$}

The expression of TLR4 is increased in PD and MSA post-mortem brain tissue, suggesting clinical relevance to TLR4 in PD and neurodegeneration in general. ${ }^{[50,74]}$ Animal experiments have been used to further elucidate the role of TLR4 in PD. TLR4 ${ }^{-/}$mice were more vulnerable to dopaminergic neuronal loss and motor problems induced by $\alpha$-synuclein overexpression, but less vulnerable to the induction of PD symptoms by 1-methyl-4-phenyl-1,2,3,6-tetrahydropyridine (MPTP) treatment. ${ }^{[95,96]}$ Furthermore, TLR4 and $\alpha$-synuclein are both necessary for LPS-induced neurodegeneration in mice. ${ }^{[97,98]}$ Therefore, mouse models support the importance of TLR4 in PD, but make no suggestion 
as to the impact of TLR4 on disease development, since TLR4 was both protective and harmful in these models. Since TLR4 is suggested to be protective in the context of $\alpha$-synuclein overexpression, TLR4 seems likely to be protective in the context of $\mathrm{PD}$, since $\alpha$-synuclein misfolding and aggregation is a hallmark of the disease. The harmful contribution of TLR4 to MPTP-induced PD seems to suggest that TLR4 might have a negative impact on the health of a subgroup of PD patients who suffer from toxininduced PD (for instance after exposure to MPTP or rotenone). Therefore, TLR4 appears mostly protective in the context of PD, but it might be harmful in the context of toxin-induced PD.

Similar to TLR2, microglia form a link between TLR4 and PD. Microglia are necessary for LPS-induced degeneration of rat cortical neurons in cell culture since these neurons themselves do not express TLR4, and nitric oxide and superoxide seem to be at least partially responsible for microglial-induced neurodegeneration. ${ }^{[97,98]}$ On the other hand, microglial TLR4 is necessary for the neuroprotective endocytosis of $\alpha$-synuclein. ${ }^{[96]}$ Microglia activated with $\alpha$-synuclein downregulate TLR4, disabling any neuroinflammatory positive feedback loop, but also reducing the ability of the microglia to take up $\alpha$-synuclein from their environment. ${ }^{[7]}$ These results are contradictive and whether TLR4 is protective or injurious in PD is still a matter of debate. The balance between the contribution of microglial TLR4 to neuroinflammation and the endocytosis of $\alpha$-synuclein might eventually determine whether this receptor is protective or harmful to the surrounding neurons. TLR4 is a promising target for future PD research. The role of TLR4 during PD can be both beneficial and harmful, and the factors determining the outcome need to be investigated in more detail. It seems that neuronal TLR4 could be protective, but the role of microglial TLR4 is still not fully understood. Resolving this debate could potentially lead to approaches aimed at turning harmful TLR4 responses into protective ones.

\section{$A D$}

One of the first lines of evidence suggesting that TLR4 might be involved in AD pathology comes from two studies where a TLR4 polymorphism was found to be protective against late onset Alzheimer's disease in the Italian population and glial cells surrounding $\mathrm{A} \beta$ plaques showed increased TLR4 expression in post mortem brain tissue. ${ }^{[99,100]}$ In a genetic AD mouse model TLR4 knock-out reduced the expression of TNF $\alpha$ and chemokine (C-C motif) ligand 4 (also known as macrophage inflammatory protein-1 $\beta$ ) in cortex homogenate, while increasing the amount of activated microglia, activated astrocytes, and $A \beta$ protein in the brain. ${ }^{[101,102]}$ Effects of TLR4 knock-out on behavior or disease progression have not been reported. The increase of $A \beta$ protein in the brain of TLR $4^{-/}$animals could be due to a lack of TLR4-mediated A $\beta$ clearance, potentially by microglia. ${ }^{[102,103]}$

Cell culture data support a pro-inflammatory role for microglia, and implicate microglia-induced inflammation in neuronal degeneration. Mouse microglia initiate an inflammatory and phagocytic response to aggregated $A \beta$ through TLR4, resulting in microglia-mediated neuronal death. ${ }^{[82,99]}$ Microglia need TLR4 to initiate LPS-stimulated A $\beta$ uptake, in fact they trigger a stronger inflammatory response to $\mathrm{A} \beta$ in combination with LPS. ${ }^{[84,102]}$

Neurons themselves respond to $A \beta$ and $A D$-related peroxidation product HNE through TLR4, resulting in apoptosis. ${ }^{[0]}$ Since little is known about the role of neuronal TLR4 in AD, it is important to start exploring the function of this receptor in animal models and in patient tissue, in a way that differentiates glial-mediated TLR4 responses from neuronal responses, for instance by selective knockdown of TLR4 in neurons in AD mouse models. Collectively, it seems that TLR4 induces an immune response in $\mathrm{AD}$ through pro-inflammatory cytokines, aimed at the removal of $A \beta$ by microglial uptake, but also phagocytosis of neurons by microglia. Insufficient removal of $A \beta$ results in an increase of $A \beta$ in the extracellular space, the subsequent activation of microglia and astrocytes, and neuronal apoptosis. In light of this hypothesis, it is also interesting to note the similarity in the role of microglial TLR4 in AD and $\mathrm{PD}$, where this receptor is responsible for the uptake of disease-specific aggregated protein and initiation of neuroinflammation, possibly causing neuronal death.

\section{Stroke}

TLR4 has both beneficial and detrimental effects in stroke models. Neurons of I/R treated mice show TLR4 upregulation, a first clue that TLR4 is involved in strokeinduced brain damage. ${ }^{[29,37]}$ Paradoxically, mice treated with low dose systemic LPS two days before I/R injury had smaller infarct sizes and less neuroinflammation in the brain, while TLR4 ${ }^{-/}$mice had less stroke-induced brain damage and less neurological deficits after $\mathrm{I} / \mathrm{R}$ treatment. ${ }^{[29,104]}$ Although these results do not suggest a beneficial or harmful role of TLR4 in stroke, the data are not mutually exclusive. TLR4 stimulation before stroke seems to be protective, while TLR4 stimulation during stroke seems detrimental. This hypothesis is supported by in vitro experiments. Increased TLR4 activity does not increase neuronal death, and TLR4 stimulation 
can be beneficial to neuronal survival at low concentra tions. ${ }^{[43,105,54,106]}$ On the other hand, glucose deprivation increased TLR4 expression and cell death in neuronal cultures while TLR4 ${ }^{--}$neurons were less susceptible to glucose deprivation induced cell death. ${ }^{[29,37]}$ In agreement with the in vivo results, it seems that TLR4 stimulation per se is not harmful to neurons and it might even be beneficial. During stroke TLR4 has a negative impact on neuronal survival, possibly in part through glucose deprivation, but most likely also as the result of a more profound inflammatory process. ${ }^{[107]}$ In relation to the opposing effects of TLR4 in PD, it is curious that TLR4 can have either protective or detrimental effects in the context of stroke.

\section{TLR8}

In innate immune cells TLR8 functions as an endosomal receptor that recognizes viral singlestranded RNA. Stimulation of TLR8 induces the activation of the My88 signaling pathway leading to an anti-viral response. ${ }^{[108]}$

The role of TLR8 in PD and AD has not yet been studied in detail, and is therefore unknown. In stroke patients a higher level of TLR8 mRNA expression in whole blood sample was positively correlated with poor patient outcome after three months, larger infarct volume and greater inflammatory response. ${ }^{[109]}$ Similar results were found in a mouse stroke model: diseased animals had increased TLR8 mRNA expression in their brain and systemic administration of a TLR8 agonist before ischemic insult increased infarct size and neurological problems. ${ }^{[110]}$ The neuronal damage in stroke patients and mice could be mediated by neuronal TLR8, since TLR8 stimulation of neurons results in fewer and shorter neurites and apoptosis and slightly but significantly increases oxygen-glucose deprivation induced cell death, while TLR8 silencing reduced oxygen-glucose deprivation induced cell death. ${ }^{[26,110]}$ Interestingly, neurodevelopmental research has shown that TLR8 is differentially expressed in the embryonic and postnatal brain in mice. ${ }^{[25,26]}$ In the mouse brain TLR8 expression increases between embryonic day 12 and postnatal day 1 , and decreases between postnatal day 7 and adulthood. ${ }^{[26]}$ During early embryonic development TLR8 expression is high in postmitotic migrating cells, but not in the periventricular proliferative area. ${ }^{[26]}$ During late embryonic development, TLR8 was restricted to axonal tracts (including the olfactory nerve fiber layer, cortical intermediate zone, internal capsule, anterior commissure, fimbria of hippocampus and optic chiasm). ${ }^{[26]}$ Postnatal expression is diffuse throughout the brain and located in soma. ${ }^{[2]}$ This indicates a potential role of TLR8 in brain development. Considering how little is known about its function in the nervous system, specifically on neurons, both the fields of neurodevelopment and neurodegeneration have much to explore with regards to TLR8. This TLR could be considered critical to study the role of TLRs on neurons in neurodegeneration, and PD in particular.

\section{NEURONAL TLRS AND VIRAL INFECTIONS}

In the previous sections we have discussed that TLRs play an important role in microglial-mediated neuroinflammation of neurodegenerative diseases. In this context it is extremely relevant to investigate further the TLR-induced immune-like functions of neurons and to understand the role of neurons in neuroinflammation. Viral infections offer useful conditions to study TLR-mediated neuronal immune functions, because neurons respond to viral infections by upregulating TLR and secreting IFN.

Neurons upregulate TLR3 and TLR4 mRNA in response to HIV and adenovirus infection, they also upregulate IFN- $\beta$ mRNA in response to Sendai virus, and increase IFN production after TLR3 and TLR8 stimulation. ${ }^{[16,27,45,111]}$ TLR3 and TLR8 are virus-sensing receptors and virus-infected cells use IFNs to signals to the neighboring cells that an infection is ongoing and to induce an immune response from nearby immune cells (or glial cells). All together, such findings suggest that neurons can act as immune cells. These neuronal TLR-mediated immune responses seem to be protective to the neurons themselves. Stimulation of TLR3 on neuronal cell lines inhibits HIV replication through IFN- $\lambda$, and TLR3 and TLR8 stimulation of a neuronal cell line results in lower susceptibility to herpes simplex virus-1 potentially through IFN- $\alpha$. Moreover, TLR3 ${ }^{-/}$primary neurons showed increased infection when exposed to West Nile virus compared to WT neurons which was not due to changes in IFN- $\alpha$ of IFN- $\beta$ production. ${ }^{[16,45,46]}$ The protective effect of TLR3 during viral infection of the CNS has been confirmed in mice: infection of TLR3 ${ }^{-/}$mice with West Nile virus resulted in a higher viral burden in neurons and increased mortality compared to WT mice. ${ }^{[46]}$ The viralsensing receptors TLR3 and TLR8 are able to initiate a protective immune-like response in neurons upon viral challenge. Unfortunately, it is not clear whether TLR2 or TLR4 have a similar potential to protect neurons against pathogenic (bacterial) attack, and what the resulting immune response would be. Therefore, it is interesting to investigate a wide range of possible immune-like responses in neuronal cultures exposed to endogenous and exogenous TLR2 and TLR4 stimuli.

\section{CONCLUSION}

This review summarizes the relevance of TLRs in the 
nervous system, and especially in neurodegenerative pathologies. Current literature shows that several neuronal TLRs are involved in the development of the nervous system and in neurodegenerative diseases. Neuronal TLRs are important for NPC proliferation, axonal growth, cell survival and in defense against viral infections. The capacity of TLR-stimulated neurons to respond as immune-like cells (production of cytokines and induction of apoptosis) is of special interest for neurodegenerative diseases, since microglial-mediated neuroinflammation is a feature of neurodegenerative diseases. These results raise the question whether neurons are active contributing to neuroinflammatory degenerative process such as PD. TLR2, TLR3, TLR4 and TLR8 are all important for neuronal function and are implicated in PD, AD and stroke. This suggests that these TLRs should be investigated further in PD and other diseases as the first innate immune receptors on neurons.

Neuronal TLR2 has divergent functions in the nervous system. It responds to tissue damage during stroke, and allows neurons to respond to the neuroinflammatory environment of AD pathology. It is interesting to analyze the involvement of neuronal TLR2 in neurodegenerative diseases other than stroke and AD. Elucidating the role of neuronal TLR2 in PD is very attractive, since microglial TLR2 has already been described in PD pathology. ${ }^{[49,73,77,78]}$ We hypothesize that $\alpha$-synuclein triggers neuroinflammation through microglial TLR2, initiating a positive feedback loop by increasing TLR2 expression on the microglia, resulting in neurodegeneration and disease progression. The contribution of neuronal TLR2 in this process is yet unknown, and could be evaluated by studying PD mouse models with a specific knock-out of TLR2 in neurons, and by studying the immune response of neurons activated with TLR2 stimuli in culture.

Neuronal TLR3 regulates cortical development and neurogenesis and is able to initiate immunelike responses in response to viral infections. This provides an interesting perspective to explore the function of neuronal TLR3 in neurodegenerative diseases, since we hypothesize that neuronal TLR3 will be detrimental in this context, and because viral infections could cause PD through the development of encephalopathy. ${ }^{[112]}$ Expression patterns of TLR3 in brain tissue of early and late PD would shed light on whether TLR3 is indeed an interesting candidate for future PD research, and what role neuronal TLR3 might play in disease development.

TLR4 is a very promising target for future PD research. The effect of TLR4 during PD can be both beneficial and harmful, but the factors determining the outcome are yet unknown. It is conceivable that neuronal TLR4 could be protective, but the role of microglial TLR4 is still in uncertain. One explanation for the confounding function of TLR4 in PD needs to be sought in the interaction between TLR4 stimulation and the stimulation of other receptors. Such interactions are known to occur for TLR4, in fact neuronal TLR4 interacts with the transient receptor potential cation channel V1 receptor to transduce itch signals and possibly to transduce pain caused by bacterial infections. ${ }^{[55,113]}$ These data open up a new scenario of research in PD, particularly using specific neuronal TLR4 deficient animals, especially if this knock-out can be initiated before, during and after PD initiation, since the beneficial or detrimental effects of TLR4 in stroke seem to be dependent on the timing of TLR4 stimulation in relation to stroke. Similarly, the study of the effects of TLR4 stimulation in neuronal cultures in combination with (microglial) immune signals known to be important in PD pathology represents also another research direction.

TLR8 influences neuronal growth and survival and is also important for the initiation of the immune response during neuronal viral infections. The implications for neurodegenerative diseases are manifold, since viral infections have been linked to PD and a better understanding of the mechanisms underlying neuronal survival could help to reduce neuronal death. ${ }^{[12]}$ Since so little is known about TLR8, further investigation about the role of this receptor represents an opportunity for future PD research. Neuronal TLRs are an emerging research area, which will have implications for neurodevelopmental, neurodegenerative and neuroinflammatory research. To date neuronal TLR2-4 and neuronal TLR8 are known to be promising candidates for future studies. Elucidation of the function of other neuronal TLRs requires further research that would lead to a better understanding of the interaction between the nervous system and the immune system.

\section{Financial support and sponsorship}

This review was supported by Utrecht University Focus \& Mass Program Drug Innovation Exploring neuro-immunomodulatory targets for drugs and medical food concepts in CNS disorders and chronic inflammatory intestinal diseases.

\section{Conflicts of interest}

J. Garssen is employee at Nutricia research, Utrecht, the Netherlands.

\section{REFERENCES}

1. Hashimoto $\mathrm{C}$, Hudson KL, Anderson KV. The Toll gene of 
Drosophila, required for dorsal-ventral embryonic polarity, appears to encode a transmembrane protein. Cell 1988;52:269-79.

2. Akira S, Uematsu S, Takeuchi O. Pathogen recognition and innate immunity. Cell 2006;124:783-801.

3. Kawai T, Akira S. TLR signaling. Cell Death Differ 2006;13:816-25

4. Kumar H, Kawai T, Akira S. Pathogen recognition in the innate immune response. Biochem J 2009;420:1-16.

5. Wagner $\mathrm{H}$. Endogenous TLR ligands and autoimmunity. Adv Immunol 2006;91:159-73.

6. Hornung V, Rothenfusser S, Britsch S, Krug A, Jahrsdörfer B Giese T, Endres S, Hartmann G. Quantitative expression of toll-like receptor 1-10 mRNA in cellular subsets of human peripheral blood mononuclear cells and sensitivity to $\mathrm{CpG}$ oligodeoxynucleotides. $J$ Immunol 2002;168:4531-7.

7. Kawasaki T, Kawai T. Toll-like receptor signaling pathways. Front Immunol 2014;5:461.

8. Tak PP, Firestein GS. NF-kappaB: a key role in inflammatory diseases. J Clin Invest 2001;107:7-11.

9. Prehaud C, Megret F, Lafage M, Lafon M. Virus infection switches TLR-3-positive human neurons to become strong producers of beta interferon. $J$ Virol 2005;79:12893-904.

10. Wadachi R, Hargreaves KM. Trigeminal nociceptors express TLR4 and CD14: a mechanism for pain due to infection. $J$ Dent Res 2006;85:49-53.

11. Lafon $\mathrm{M}$, Megret $\mathrm{F}$, Lafage $\mathrm{M}$, Prehaud $\mathrm{C}$. The innate immune facet of brain: human neurons express TLR-3 and sense viral dsRNA. J Mol Neurosci 2006;29:185-194.

12. Jackson AC, Rossiter JP, Lafon M. Expression of Toll-like receptor 3 in the human cerebellar cortex in rabies, herpes simplex encephalitis, and other neurological diseases. J Neurovirol 2006;12:229-34

13. Barajon I, Serrao G, Arnaboldi F, Opizzi E, Ripamonti G, Balsari A, Rumio C. Toll-like receptors 3, 4, and 7 are expressed in the enteric nervous system and dorsal root ganglia. $J$ Histochem Cytochem 2009;57:1013-23.

14. Goethals S, Ydens E, Timmerman V, Janssens S. Toll-like receptor expression in the peripheral nerve. Glia 2010;58:1701-9.

15. Kurt-Jones EA, Chan M, Zhou S, Wang J, Reed G, Bronson R, Arnold MM, Knipe DM, Finberg RW. Herpes simplex virus 1 interaction with Toll-like receptor 2 contributes to lethal encephalitis. Proc Natl Acad Sci U S A 2004;101:1315-20.

16. Zhou Y, Ye L, Wan Q, Zhou L, Wang X, Li J, Hu S, Zhou D, Ho W. Activation of Toll-like receptors inhibits herpes simplex virus-1 infection of human neuronal cells. J Neurosci Res 2009;87:2916-25.

17. McKimmie CS, Fazakerley JK. In response to pathogens, glial cells dynamically and differentially regulate Toll-like receptor gene expression. J Neuroimmunol 2005;169:116-25

18. Jack CS, Arbour N, Manusow J, Montgrain V, Blain M, McCrea E Shapiro A, Antel JP. TLR signaling tailors innate immune responses in human microglia and astrocytes. J Immunol 2005;175:4320-30

19. Olson JK, Miller SD. Microglia initiate central nervous system innate and adaptive immune responses through multiple TLRs. $J$ Immunol 2004;1733916-24.

20. Bsibsi M, Ravid R, Gveric D, van Noort JM. Broad expression of Tolllike receptors in the human central nervous system. $J$ Neuropathol Exp Neurol 2002;61:1013-021.

21. Ochoa-Cortes F, Ramos Lomas T, Miranda-Morales M, Spreadbury I, Ibeakanma C, Barajas-Lopez C, Vanner S. Bacterial Cell Products Signal to Mouse Colonic Nociceptive Dorsal Root Ganglia Neurons. Am J Physiol liver Physiol 2010;299:G723-32.

22. Esposito G, Capoccia E, Turco F, Palumbo I, Lu J, Steardo A Cuomo R, Sarnelli G, Steardo L1. Palmitoylethanolamide improves colon inflammation through an enteric glia/toll like receptor 4-dependent PPAR-alpha activation. Gut 2014;63:1300-12.

23. Turco F, Sarnelli G, Cirillo C, Palumbo I, De Giorgi F, D'Alessandro A, Cammarota M, Giuliano M, Cuomo R. Enteroglial-derived S100B protein integrates bacteria-induced Toll-like receptor signalling in human enteric glial cells. Gut 2014;63:105-15.

24. Cameron JS, Alexopoulou L, Sloane JA, DiBernardo AB, Ma Y, Kosaras B, Flavell R, Strittmatter SM, Volpe J, Sidman R, Vartanian T. Toll-like receptor 3 is a potent negative regulator of axonal growth in mammals. J Neurosci 2007;27:13033-41.

25. Ma Y, Haynes RL, Sidman RL, Vartanian T. TLR8: an innate immune receptor in brain, neurons and axons. Cell Cycle 2007;6:2859-68.

26. Ma Y, Li J, Chiu I, Wang Y, Sloane JA, Lü J, Kosaras B, Sidman RL, Volpe JJ, Vartanian T. Toll-like receptor 8 functions as a negative regulator of neurite outgrowth and inducer of neuronal apoptosis. J Cell Biol 2006;175:209-15

27. Peltier DC, Simms A, Farmer JR, Miller DJ. Human neuronal cells possess functional cytoplasmic and TLR-mediated innate immune pathways influenced by phosphatidylinositol-3 kinase signaling. $J$ Immunol 2010;184:7010-21

28. Li Y, Li H, Zhang Y, Sun X, Hanley GA, LeSage G, Zhang Y, Sun S, Peng Y, Yin D. Toll-like receptor 2 is required for opioidsinduced neuronal apoptosis. Biochem Biophys Res Commun 2010;391:426-30.

29. Tang SC, Arumugam T V, Xu X, Cheng A, Mughal MR, Pivotal role for neuronal Toll-like receptors in ischemic brain injury and functional deficits. Proc Natl Acad Sci U S A 2007;104:13798-803.

30. van der Kleij HP, Ma D, Redegeld FA, Kraneveld AD, Nijkamp FP, Bienenstock J. Functional expression of neurokinin 1 receptors on mast cells induced by IL-4 and stem cell factor. $J$ Immunol 2003;171:2074-9.

31. Rijnierse A, Kroese AB, Redegeld FA, Blokhuis BR, van der Heijden MW, Koster AS, Timmermans JP, Nijkamp FP, Kraneveld AD. Immunoglobulin-free light chains mediate antigen-specific responses of murine dorsal root ganglion neurons. J Neuroimmunol 2009;208:80-86.

32. Downes CE, Crack PJ. Neural injury following stroke: are Toll-like receptors the link between the immune system and the $\mathrm{CNS}$ ? $\mathrm{Br} J$ Pharmacol 2010;160:1872-88.

33. Snoek SA, Verstege MI, Boeckxstaens GE, van den Wijngaard $\mathrm{RM}$, de Jonge WJ. The enteric nervous system as a regulator of intestinal epithelial barrier function in health and disease. Expert Rev Gastroenterol Hepatol 2010;4:637-51.

34. Wood JD. Visceral pain: spinal afferents, enteric mast cells, enteric nervous system and stress. Curr Ph Des 2011;17(16):1573-5.

35. Trudler D, Farfara D, Frenkel D. Toll-like receptors expression and signaling in glia cells in neuro-amyloidogenic diseases: towards future therapeutic application. Mediators Inflamm 2010; pii: 497987

36. Drouin-OuelletJ, CicchettiF. Inflammationand neurodegeneration the story "retolled." Trends Pharmacol Sci 2012;33:542-51.

37. Li HY, Yuan ZY, Wang YG, Wan HJ, Hu J, Chai YS, Lei F, Xing DM, DU LJ. Role of baicalin in regulating Toll-like receptor $2 / 4$ after ischemic neuronal injury. Chin Med J (Engl) 2012;125:1586-93.

38. Paulino AD, Ubhi K, Rockenstein E, Adame A, Crews L, Letendre S, Ellis R, Everall IP, Grant I, Masliah E. Neurotoxic effects of the $\mathrm{HCV}$ core protein are mediated by sustained activation of ERK via TLR2 signaling. J Neurovirol 2011;17327-340.

39. Ziegler G, Harhausen D, Schepers C, Hoffmann O, Röhr C, Prinz V, König J, Lehrach H, Nietfeld W, Trendelenburg G. TLR2 has a detrimental role in mouse transient focal cerebral ischemia. Biochem Biophys Res Commun 2007;359:574-9.

40. Tang SC, Lathia JD, Selvaraj PK, Hoffmann O, Röhr C, Prinz V, König J, Lehrach H, Nietfeld W, Trendelenburg G. Toll-like receptor-4 mediates neuronal apoptosis induced by amyloid beta-peptide and the membrane lipid peroxidation product 4-hydroxynonenal. Exp Neurol 2008;213:114-21.

41. Hua F, Ma J, Ha T, Kelley JL, Kao RL, Schweitzer JB, Kalbfleisch $\mathrm{JH}$, Williams DL, Li C. Differential roles of TLR2 and TLR4 in acute focal cerebral ischemia/reperfusion injury in mice. Brain Res 2009; 1262:100-108.

42. Ziegler G, Freyer D, Harhausen D, Khojasteh U, Nietfeld W, Trendelenburg G. Blocking TLR2 in vivo protects againstaccumulation of inflammatory cells and neuronal injury in experimental stroke. $J$ Cereb Blood Flow Metab 2011;31:757-66.

43. Anitha M, Vijay-Kumar M, Sitaraman S V, Gewirtz AT, Srinivasan S Gut microbial products regulate murine gastrointestinal motility via Toll-like Receptor 4 signaling. Gastroenterology 2012;143:1006-16.

44. Chuang JH, Chuang HC, Huang CC, Wu CL, Du YY, Kung ML, Chen $\mathrm{CH}$, Chen SC, Tai MH. Differential toll-like receptor 3 (TLR3) expression and apoptotic response to TLR3 agonist in human neuroblastoma cells. J Biomed Sci 2011:18:65.

45. Zhou L, Wang X, Wang YJ, Activation of toll-like receptor-3 induces interferon-lambda expression in human neuronal cells. Activation of toll-like receptor-3 induces interferon-lambda expression in human neuronal cells. Neuroscience 2009;159:629-37.

46. Daffis S, Samuel MA, Suthar MS, Gale Jr M, Diamond MS Toll-like receptor 3 has a protective role against West Nile virus infection. J Virol 2008;82:10349-58.

47. Letiembre M, Liu Y, Walter S, Hao W, Pfander T, Wrede A, SchulzSchaeffer W, Fassbender K. Screening of innate immune receptors in neurodegenerative diseases: a similar pattern. Neurobiol Aging 
2009;30:759-68.

48. Ros-BernalF, HunotS, HerreroMT, Microglial glucocorticoid receptors play a pivotal role in regulating dopaminergic neurodegeneration in parkinsonism. Microglial glucocorticoid receptors play a pivotal role in regulating dopaminergic neurodegeneration in parkinsonism. Proc Natl Acad Sci U S A 2011;108:6632-7.

49. Kim C, Ho DH, Suk JE, You S, Michael S, Kang J, Joong Lee S, Masliah E, Hwang D, Lee HJ, Lee SJ. Neuron-released oligomeric alpha-synuclein is an endogenous agonist of TLR2 for paracrine activation of microglia. Nat Commun 2013;4:1562.

50. Stefanova N, Reindl M, Neumann M, Kahle PJ, Poewe W, Wenning GK. Microglial activation mediates neurodegeneration related to oligodendroglial alpha-synucleinopathy: implications for multiple system atrophy. Mov Disord 2007;22:2196-203.

51. Brudek T, Winge K, Agander TK, Pakkenberg B. Screening of Toll-like receptors expression in multiple system atrophy brains. Neurochem Res 2013;38:1252-9.

52. Panaro MA, Lofrumento DD, Saponaro C, De Nuccio F, Cianciulli A, Mitolo V, Nicolardi G. Expression of TLR4 and CD14 in the central nervous system (CNS) in a MPTP mouse model of Parkinson's-like disease. Immunopharmacol Immtoxicol 2008;30:729-40.

53. Landreth GE, Reed-Geaghan EG. Toll-like receptors in Alzheimer's disease. Curr Top Microbiol Immunol 2009;336:137-53.

54. Kunda PE, Cavicchia JC, Acosta CG. Lipopolysaccharides and trophic factors regulate the LPS receptor complex in nodose and trigeminal neurons. Neuroscience 2014;280:60-72.

55. Min H, Lee H, Lim H, Jang YH, Chung SJ, Lee CJ, Lee SJ. TLR4 enhances histamine-mediated pruritus by potentiating TRPV1 activity. Mol Brain 2014;7:59.

56. Maslinska D, Laure-Kamionowska M, Maslinski S. Toll-like receptors in rat brains injured by hypoxic-ischaemia or exposed to staphylococcal alpha-toxin. Folia Neuropathol 2004;42:125-32.

57. Arciszewski MB, Sand E, Ekblad E. Vasoactive intestinal peptide rescues cultured rat myenteric neurons from lipopolysaccharide induced cell death. Regul Pept 2008;146:218-223.

58. Lathia JD, Okun E, Tang SC, Griffioen K, Cheng A, Mughal MR, Laryea G, Selvaraj PK, ffrench-Constant C, Magnus T, Arumugam TV, Mattson MP. Toll-like receptor 3 is a negative regulator of embryonic neural progenitor cell proliferation. J Neurosci 2008;28:13978-84.

59. Menager P, Roux P, Megret F, Bourgeois JP, Le Sourd AM, Danckaert A, Lafage M, Préhaud C, Lafon M. Toll-like receptor 3 (TLR3) plays a major role in the formation of rabies virus Negri Bodies. PLoS Pathog 2009;5:e1000315.

60. Pleasure SJ, Page C, Lee VM. Pure, postmitotic, polarized human neurons derived from NTera 2 cells provide a system for expressing exogenous proteins in terminally differentiated neurons. J Neurosci 1992;12:1802-15

61. Schwartz CM, Spivak CE, Baker SC, McDaniel TK, Loring JF, Nguyen C, Chrest FJ, Wersto R, Arenas E, Zeng X, Freed WJ, Rao MS. NTera2: a model system to study dopaminergic differentiation of human embryonic stem cells. Stem Cells Dev 2005;14:517-34

62. Lee H, Lee S, Cho IH, Lee SJ. Toll-like receptors: sensor molecules for detecting damage to the nervous system. Curr Protein Pept Sci 2013;14:33-42.

63. Carpentier PA, Duncan DS, Miller SD. Glial toll-like receptor signaling in central nervous system infection and autoimmunity. Brain Behav Immun 2008;22:140-47.

64. Aravalli RN, Peterson PK, Lokensgard JR. Toll-like receptors in defense and damage of the central nervous system. JNeuroimmune Pharmacol 2007;2:297-312.

65. Lehnardt S. Innate immunity and neuroinflammation in the CNS: the role of microglia in Toll-like receptor-mediated neuronal injury. Glia 2010;58:253-263

66. Lee H, Jo EK, Choi SY, Oh SB, Park K, Kim JS, Lee SJ. Necrotic neuronal cells induce inflammatory Schwann cell activation via TLR2 and TLR3: implication in Wallerian degeneration. Biochem Biophys Res Commun 2006;350:742-7.

67. Oliveira RB, Ochoa MT, Sieling PA, Rea TH, Rambukkana A, Sarno EN, Modlin RL. Expression of Toll-like receptor 2 on human Schwann cells: a mechanism of nerve damage in leprosy. Infect Immun 2003;71:1427-33.

68. Lee H, Park C, Cho IH, Kim HY, Jo EK, Lee S, Kho HS, Choi SY, Oh SB, Park K, Kim JS, Lee SJ. Double-stranded RNA induces iNOS gene expression in Schwann cells, sensory neuronal death, and peripheral nerve demyelination. Glia 2007;55:712-22.

69. Cheng C, Qin Y, Shao X, Wang H, Gao Y, Cheng M, Shen A.
Induction of TNF-alpha by LPS in Schwann cell is regulated by MAPK activation signals. Cell Mol Neurobiol 2007;27:909-21.

70. Brun P, Gobbo S, Caputi V, Spagnol L, Schirato G, Pasqualin M, Levorato E, Palù G, Giron MC, Castagliuolo I. Toll like receptor-2 regulates production of glial-derived neurotrophic factors in murine intestinal smooth muscle cells. Mol Cell Neurosci 2015;68:24-35.

71. van Bergenhenegouwen J, Plantinga TS, Joosten LA, Netea MG, Folkerts G, Kraneveld AD, Garssen J, Vos AP. TLR2 \& Co: a critical analysis of the complex interactions between TLR2 and coreceptors. J Leukoc Biol 2013;94:885-902.

72. Oosting M, Cheng S-C, Bolscher JM, Vestering-Stenger R, Plantinga TS, Verschueren IC, Arts P, Garritsen A, van Eenennaam H, Sturm P, Kullberg BJ, Hoischen A, Adema GJ, van der Meer JW, Netea MG, Joosten LA. Human TLR10 is an anti-inflammatory patternrecognition receptor. Proc Natl Acad Sci U S A 2014;111:E4478-84.

73. Doorn KJ, Moors T, Drukarch B, van de Berg WD, Lucassen PJ, van Dam AM. Microglial phenotypes and toll-like receptor 2 in the substantia nigra and hippocampus of incidental Lewy body disease cases and Parkinson's disease patients. Acta Neuropathol Commun 2014;2:90-1.

74. Drouin-Ouellet J, St-Amour I, Saint-Pierre M, Lamontagne-Proulx J, Kriz J, Barker RA, Cicchetti F. Toll-like receptor expression in the blood and brain of patients and a mouse model of Parkinson's Disease. Int $J$ Neuropsychopharmacol 2014; pii: pyu103.

75. Kalinderi K, Bostantjopoulou S, Katsarou Z, Fidani L. TLR9 -1237 T/C and TLR2 -194 to -174 del polymorphisms and the risk of Parkinson's disease in the Greek population: a pilot study. Neurol Sci 2013;34:679-82

76. Noguchi E, Nishimura F, Fukai H, Kim J, Ichikawa K, Shibasaki $\mathrm{M}$, Arinami T. An association study of asthma and total serum immunoglobin E levels for Toll-like receptor polymorphisms in a Japanese population. Clin Exp Allergy 2004;34:177-83.

77. Beraud D, Twomey M, Bloom B, Mittereder A, Ton V, Neitzke K, Chasovskikh S, Mhyre TR, Maguire-Zeiss KA. alpha-Synuclein Alters Toll-Like Receptor Expression. Front Neurosci 2011;5:80.

78. Roodveldt C, Labrador-Garrido A, Gonzalez-Rey E, Lachaud CC, Guilliams T, Fernandez-Montesinos R, Benitez-Rondan A, Robledo G, Hmadcha A, Delgado M, Dobson CM, Pozo D. Preconditioning of Microglia by $\alpha$-Synuclein Strongly Affects the Response Induced by Toll-like Receptor (TLR) Stimulation. PLoS One 2013;8:e79160.

79. Frank S, Copanaki E, Burbach GJ, Müller UC, Deller T. Differential regulation of toll-like receptor mRNAs in amyloid plaque-associated brain tissue of aged APP23 transgenic mice. Neurosci Lett 2009;453:41-4.

80. Jana M, Palencia CA, Pahan K. Fibrillar amyloid-beta peptides activate microglia via TLR2: implications for Alzheimer's disease. J Immunol 2008;181:7254-62.

81. Richard KL, Filali M, Prefontaine P, Rivest S. Toll-like receptor 2 acts as a natural innate immune receptor to clear amyloid beta 1-42 and delay the cognitive decline in a mouse model of Alzheimer's disease. J Neurosci 2008;28:5784-93.

82. Reed-Geaghan EG, Savage JC, Hise AG, Landreth GE. CD14 and toll-like receptors 2 and 4 are required for fibrillar $A\{b e t a\}$ stimulated microglial activation. J Neurosci 2009;29:11982-92.

83. Schutze S, Loleit T, Zeretzke M, Bunkowski S, Brück W, Ribes S, Nau R. Additive Microglia-Mediated Neuronal Injury Caused by Amyloidbeta and Bacterial TLR Agonists in Murine Neuron-Microglia CoCultures Quantified by an Automated Image Analysis using Cognition Network Technology. J Alzheimers Dis 2012;31:651-57.

84. Lotz M, Ebert S, Esselmann H, Iliev AI, Prinz M, Wiazewicz N, Wiltfang J, Gerber J, Nau R. Amyloid beta peptide 1-40 enhances the action of Toll-like receptor- 2 and -4 agonists but antagonizes Toll-like receptor-9-induced inflammation in primary mouse microglial cell cultures. J Neurochem 2005;94:289-98.

85. Li H-Y, Hu J, Zhao S, Yuan ZY, Wan HJ, Lei F, Ding Y, Xing DM, Du LJ. Comparative Study of the Effect of Baicalin and Its Natural Analogs on Neurons with Oxygen and Glucose Deprivation Involving Innate Immune Reaction of TLR2/TNF. $J$ Biomed Biotechnol 2012;2012:267890.

86. Lien E, Ingalls RR. Toll-like receptors. Crit Care Med 2002;30:S1-S11.

87. Jang H, Boltz D, Sturm-Ramirez K, Highly pathogenic H5N1 influenza virus can enter the central nervous system and induce neuroinflammation and neurodegeneration. Highly pathogenic H5N1 influenza virus can enter the central nervous system and induce neuroinflammation and neurodegeneration. Proc Natl Acad Sci U S A 2009;106:14063-8. 
88. Zhou L, Miranda-Saksena M, Saksena NK. Viruses and neurodegeneration. Virol J 2013;10:172.

89. Wu WY, Kang KH, Chen SL, Chiu SY, Yen AM, Fann JC, Su CW, Liu $\mathrm{HC}$, Lee CZ, Fu WM, Chen HH, Liou HH. Hepatitis C virus infection: a risk factor for Parkinson's disease. J Viral Hepat 2015;22:784-91.

90. Moulignier A, Gueguen A, Lescure FX, Ziegler M, Girard PM, Cardon B, Pialoux G, Molina JM, Brandel JP, Lamirel C. Does hiv infection alter parkinson's disease? J Acquir Immune Defic Syndr 2015;70:129-36.

91. Woulfe JM, Gray MT, Gray DA, Munoz DG, Middeldorp JM. Hypothesis: a role for EBV-induced molecular mimicry in Parkinson's disease. Parkinsonism Relat Disord 2014;20:685-94.

92. Vabulas RM, Ahmad-Nejad P, da Costa C, Miethke T, Kirschning $\mathrm{CJ}$, Häcker H, Wagner H. Endocytosed HSP60s use toll-like receptor 2 (TLR2) and TLR4 to activate the toll/interleukin-1 receptor signaling pathway in innate immune cells. $J$ Biol Chem 2001;276:31332-9.

93. Asea A, Rehli M, Kabingu E, Boch JA, Bare O, Auron PE, Stevenson MA, Calderwood SK. Novel signal transduction pathway utilized by extracellular HSP70: role of toll-like receptor (TLR) 2 and TLR4. $J$ Biol Chem 2002;277:15028-34.

94. Biragyn A, Ruffini PA, Leifer CA, Klyushnenkova E, Shakhov A, Chertov O, Shirakawa AK, Farber JM, Segal DM, Oppenheim JJ, Kwak LW. Toll-like receptor 4-dependent activation of dendritic cells by beta-defensin 2. Science 2002;298:1025-9.

95. Noelker C, Morel L, Lescot T, Osterloh A, Alvarez-Fischer D, Breloer M, Henze C, Depboylu C, Skrzydelski D, Michel PP, Dodel RC, Lu L, Hirsch EC, Hunot S, Hartmann A. Toll like receptor 4 mediates cell death in a mouse MPTP model of Parkinson disease. Sci Rep 2013;3:1393.

96. Stefanova N, Fellner L, Reindl M, Masliah E, Poewe W, Wenning GK. Toll-like receptor 4 promotes alpha-synuclein clearance and survival of nigral dopaminergic neurons. Am J Pathol 2011;179:954-63.

97. Gao HM, Kotzbauer PT, Uryu K, Leight S, Trojanowski JQ, Lee VM. Neuroinflammation and oxidation/nitration of alphasynuclein linked to dopaminergic neurodegeneration. $J$ Neurosci 2008:28:7687-98.

98. Lehnardt S, Massillon L, Follett P, Jensen FE, Ratan R, Rosenberg $\mathrm{PA}$, Volpe JJ, Vartanian T. Activation of innate immunity in the CNS triggers neurodegeneration through a Toll-like receptor 4-dependent pathway. Proc Natl Acad Sci U S A 2003;100:8514-9.

99. Walter S, Letiembre M, Liu Y, Heine H, Penke B, Hao W, Bode B, Manietta N, Walter J, Schulz-Schuffer W, Fassbender K. Role of the toll-like receptor 4 in neuroinflammation in Alzheimer's disease. Cell Physiol Biochem 2007;20:947-956.

100. Minoretti P, Gazzaruso C, Vito CD, Emanuele E, Bianchi M, Coen E, Reino M, Geroldi D. Effect of the functional toll-like receptor 4 Asp299Gly polymorphism on susceptibility to late-onset Alzheimer's disease. Neurosci Lett 2006;391:147-9.

101. Jin J-J, Kim H-D, Maxwell JA, Li L, Fukuchi K. Toll-like receptor 4-dependent upregulation of cytokines in a transgenic mouse model of Alzheimer's disease. J Neuroinflammation 2008;5:3006-19.

102. Tahara K, Kim HD, Jin JJ, Maxwell JA, Li L, Fukuchi K. Role of toll-like receptor signalling in Abeta uptake and clearance. Brain 2006;129:3006-19.

103. Herber DL, Roth LM, Wilson D, Wilson N, Mason JE, Morgan $\mathrm{D}$, Gordon MN. Time-dependent reduction in $A \beta$ levels after intracranial LPS administration in APP transgenic mice. Exp Neurol 2004;190:245-53.

104. Rosenzweig HL, Lessov NS, Henshall DC, Minami M, Simon RP, Stenzel-Poore MP. Endotoxin preconditioning prevents cellular inflammatory response during ischemic neuroprotection in mice. Stroke 2004;35:2576-81.

105. De Paola M, Mariani A, Bigini P, Peviani M, Ferrara G, Molteni M, Gemma S, Veglianese P, Castellaneta V, Boldrin V, Rossetti C, Chiabrando C, Forloni G, Mennini T, Fanelli R. Neuroprotective effects of Toll-like receptor 4 antagonism in spinal cord cultures and in a mouse model of motor neuron degeneration. Mol Med 2012;18:971-81.

106. Zeng KW, Zhang T, Fu H, Liu GX, Wang XM. Schisandrin B exerts anti-neuroinflammatory activity by inhibiting the Toll-like receptor 4-dependent MyD88/IKK/NF-kappaB signaling pathway in lipopolysaccharide-induced microglia. Eur $J$ Pharmacol 2012;692:29-37.

107. Jin R, Yang G, Li G. Inflammatory mechanisms in ischemic stroke: role of inflammatory cells. J Leukoc Biol 2010;87:779-89.

108. Ohto U, Tanji H, Shimizu T. Structure and function of toll-like receptor 8. Microbes Infect 2014;16:273-82.

109. Brea D, Sobrino T, Rodríguez-Yáñez M, Ramos-Cabrer P, Agulla J, Rodríguez-González R, Campos F, Blanco M, Castillo J. Tolllike receptors 7 and 8 expression is associated with poor outcome and greater inflammatory response in acute ischemic stroke. Clin Immunol 2011;139:193-8.

110. Tang SC, Yeh SJ, Li YI, Wang YC, Baik SH, Santro T, Widiapradja A, Manzanero S, Sobey CG, Jo DG, Arumugam TV, Jeng JS. Evidence for a detrimental role of TLR8 in ischemic stroke. Exp Neurol 2013;250:341-347.

111. Piersanti S, Astrologo L, Licursi V, Costa R, Roncaglia E, Gennetier A, Ibanes S, Chillon M, Negri R, Tagliafico E, Kremer EJ, Saggio I. Differentiated neuroprogenitor cells incubated with human or canine adenovirus, or lentiviral vectors have distinct transcriptome profiles. PLoS One 2013;8:e69808.

112. Jang H, Boltz DA, Webster RG, Smeyne RJ. Viral parkinsonism. Biochim Biophys Acta (BBA)-Molecular Basis Dis 2009;1792:714-21.

113. Diogenes A, Ferraz CC, Akopian AN, Henry MA, Hargreaves KM. LPS sensitizes TRPV1 via activation of TLR4 in trigeminal sensory neurons. J Dent Res 2011;90:759-64. 